\title{
Invasive fungal disease in PICU: epidemiology and risk factors
}

\author{
Olivier Brissaud ${ }^{1 *}$, Julie Guichoux¹, Jerome Harambat ${ }^{1}$, Olivier Tandonnet ${ }^{1}$ and Theoklis Zaoutis $^{2}$
}

\begin{abstract}
Candida and Aspergillus spp. are the most common agents responsible for invasive fungal infections in children. They are associated with a high mortality and morbidity rate as well as high health care costs. An important increase in their incidence has been observed during the past two decades. In infants and children, invasive candidiasis is five times more frequent than invasive aspergillosis. Candida sp. represents the third most common agent found in healthcare-associated bloodstream infections in children. Invasive aspergillosis is more often associated with hematological malignancies and solid tumors. Recommendations concerning prophylactic treatment for invasive aspergillosis have been recently published by the Infectious Diseases Society of America. Candida albicans is the main Candida sp. associated with invasive candidiasis in children, even if a strong trend toward the emergence of Candida non-albicans has been observed. The epidemiology and the risk factors for invasive fungal infections are quite different if considering previously healthy children hospitalized in the pediatric intensive care unit, or children with a malignancy or a severe hematological disease (leukemia). In children, the mortality rate for invasive aspergillosis is 2.5 to 3.5 higher than for invasive candidiasis (respectively $70 \%$ vs. $20 \%$ and 30\%).
\end{abstract}

\section{Introduction}

Candida and Aspergillus spp. are the most common agents responsible for invasive fungal infections (IFI) in children. They are associated with a high mortality and morbidity rate as well as high health care costs. Their incidence has dramatically increased within the past two decades [1-3]. In children, invasive Candida infection (ICI) is five times more frequent than invasive Aspergillus infection (IAI). Candida spp. is the third most common agent implicated in healthcare-associated bloodstream infections in children [4-8]. IAI is more often associated with hematological malignancies and solid tumors. Strong recommendations concerning prophylactic treatment for IAI have been published [9]. Although Candida albicans is still the main Candida sp. associated with ICI in children, a strong trend toward the emergence of Candida non-albicans has been observed. This could be linked to the use of fluconazole prophylaxis in some patients [2,4]. The epidemiology/ risk factors for IFI are quite different between previously

\footnotetext{
*Correspondence: Olivier.brissaud@chu-bordeaux.fr

'Pediatric and Neonatal Intensive Care Unit, The Children's' Hospital of

Bordeaux, Place Amélie Raba Léon, 33076 Bordeaux Cedex, France

Full list of author information is available at the end of the article
}

healthy children hospitalized in the pediatric intensive care unit (PICU) and children whose hospitalization is related to malignancy or a severe hematological disease (leukemia). Indeed, in the second group, the reported incidence is approximately $5 \%$ with a mortality rate of approximately $60 \%$ [10]. The crude mortality of patients with IFI is $32 \%$ [11]. The mortality rate due to IAI in children is approximately $70 \%$ despite appropriate treatment, whereas it is between $20 \%$ and $30 \%$ for ICI $[5,12]$.

\section{Fungal infections and nosocomial infections}

In France, a 1-day national survey of nosocomial infections performed in 2001 included 21,596 children younger than aged 18 years $(7.1 \%$ of all hospitalized children) [13]. Overall, $2.4 \%$ presented with a nosocomial infection (1.2\% for newborns and $3.3 \%$ for children). ICI, in this study, accounted for $4.4 \%$ of all infections, regardless of which unit the children were hospitalized in. The rate of nosocomial infections in children hospitalized in PICUs was approximately 15\% [13]. Posfay-Barbe et al. reported a Candida infection rate of $10 \%$ in children younger than aged 18 years in the United States, regardless of age and hospital unit [11]. In 1999, Richards et al. [8] showed that Candida

\section{实}


spp. was implicated in $9.4 \%$ of bloodstream infections in PICUs in the United States. An Israeli study [14] found Candida spp in $14.4 \%$ of bloodstream infections in PICUs. Aspergillus was found in $0.5 \%$ of lung infections and $0.1 \%$ of sepsis [8].

\section{Invasive candidiasis in the PICU Epidemiology}

ICI in the PICU presents as candidemia or disseminated candidiasis (kidney, liver, eye, etc.). In 2000, a large U.S. study on the epidemiology and outcome of hospitalized adults and children with candidemia showed a higher candidemia rate among hospitalized children than adults (43 vs. 30 cases per 100,000 admissions, respectively) [7]. Dutta et al. reported an increase in the incidence of candidemia in their institution (Houston, Texas), rising from 0.06 to 0.3 per 1,000 inpatients from 2000 to 2009 (with an increase from to 2000 to 2004 followed by a stabilization after 2005) [15].

ICI is a very severe disease with an attributable mortality in children between $20 \%$ to $30 \%$ [5,12], and a mortality rate among children with ICI between $16 \%$ to $31 \%$ [5]. Depending on the study, Candida is either the second, third, or fourth causative agent for sepsis in hospitalized children, after coagulase negative Staphylococci, enterococci, and Staphylococcus aureus [4-8]. Singhi et al. reported recently that Candida spp colonization occurs in approximately $70 \%$ of pediatric patients in the PICU [16]. The risk of colonization is particularly important in small children [17]. In the report by Zaoutis et al., the incidence of candidemia in the PICU was 3.5 per 1,000 admissions [3].

Candida albicans is more predominant in children than in adults. Moreover, Candida albicans remains, in various studies, the most common fungal agent associated with ICI regardless of age (55\%), followed by C. parapsilosis (17.5\%), C. tropicalis (10\%), C glabrata, and krusei (2-3\% each) [4]. Although Candida albicans is the main Candida species in children, some strains are associated with specific conditions: $C$ glabrata among surgical patients or those with a central venous line; C. tropicalis among patients with malignant disease or neutropenia; and C. parapsilosis among infants or those on parenteral nutrition.

Pfaller [18] reported data on blood samples from 79 medical centers throughout the world and confirmed these results in 256 children aged 0 to 19 years: $50 \%$ of patients experienced infection with C. albicans, $28.5 \%$ with $C$. parapsilosis, $12.9 \%$ with $C$. tropicalis, $2 \%$ with $C$. glabrata, and $0.8 \%$ with C. krusei.

\section{Risk factors}

Hospitalization in the PICU represents a risk factor for ICI. Other risk factors include presence of a central venous line, parenteral nutrition, preexisting bacterial infection, immunocompromised status, recent surgery, dialysis, prolonged use of vancomycin, and mechanical ventilation [6]. Table 1 summarizes the risk factors for developing ICI in children hospitalized in the PICU. These risk factors can coexist. The role of the central venous line in the occurrence of disseminated candidiasis is well known; it increases threefold the risk for developing a disseminated infection (odds ratio [OR] = 3.0; 95\% confidence interval [CI], 1.2-7.8; $p=0.02$ ) for patients who have a central venous line in place for 3 days [19]. The recommendations given by the Infectious Diseases Society of America are very clear regarding central line replacement in case of ICI: "Central venous catheters should be removed when candidemia is documented, if at all possible"[9]. Predicting the risk for children to develop candidemia in the PICU poses an

Table 1 Risk factors for Invasive Candida Infection in children (from [3])

\begin{tabular}{|c|c|c|}
\hline Risk factors for invasive candidiasis & Unadjusted odds ratio & $95 \%$ Confidence interval \\
\hline Malignancy & 3.22 & $1.36-7.6$ \\
\hline Presence of a central venous catheter & 13.4 & $4.8-37.42$ \\
\hline Presence of a arterial catheter & 1.77 & $1.02-3.06$ \\
\hline Receipt of total parenteral nutrition & 5.3 & $2.8-10.05$ \\
\hline Neutropenia within 15 days & 5.58 & $1.12-27.79$ \\
\hline Non-candidal blood stream infection within 15 days & 2.47 & $1.35-4.52$ \\
\hline Receipt of antifungal agents within 15 days & 2.86 & $1.44-5.66$ \\
\hline Receipt of antibiotics within 15 days & 5.44 & $1.87-15.77$ \\
\hline Parenteral or oral vancomycin during 1-3 days & 2.56 & $1.27-5.16$ \\
\hline Parenteral or oral vancomycin $\geq 4$ days & 3.17 & $1.73-5.82$ \\
\hline Extended-spectrum cephalosporins $\geq 4$ days & 2.31 & $1.26-4.22$ \\
\hline Carbapenems $\geq 4$ days & 3.29 & $1.1-9.89$ \\
\hline Aminoglycosides & 2.09 & $1.17-3.74$ \\
\hline Agents covering anaerobic organisms $\geq 4$ days ${ }^{a}$ & 2.3 & $1.29-4.11$ \\
\hline
\end{tabular}

ancluding ampicillin sulbactam, clindamycin, imipenem, meropenem, metronidazole, and ticarcillin-clavulanate 
important challenge. By combining various risk factors in 101 children hospitalized in the PICU, it has been shown recently [3] that the risk of ICI in this population increased from $10 \%$ (malignancy + central venous line + more than 3 days of vancomycine) to $46 \%$ (antibiotics with anti-anaerobic activity + malignancy + central venous line + total parenteral nutrition + more than 3 days of vancomycine). Based on data from studies in adult patients, some authors have suggested using antifungal prophylaxis in patients for whom the risk of candidemia is higher than $10 \%$ [20].

There is an association between ICI and Candida colonization. Singhi et al. [16] noted a positive correlation $(p=0.033)$ between colonization and candidemia among PICU patients, regardless of site of colonization. Colonization was four times more likely in patients with a central venous line. Authors compared 20 patients with candidemia and 45 patients without candidemia. Eighteen of the infected patients were colonized with Candida (90\%), whereas only 27 of the noninfected patients were colonized $(\mathrm{OR}=6$; 95\% CI, 1.2-29.1; $p=$ $0.03)$. In the literature regarding adults, many publications have reported scores or indexes based on localization of Candida colonization, and the presence or not of clinical signs, to identify people at risk of developing ICI [21-23]. Pittet et al. showed the value of using a Candida colonization index (ratio of the number of distinct, non-blood, body sites, screening positive for Candida spp to the total number of distinct body sites tested) to identify colonized patients who should be treated preemptively with antifungal therapy [23]. The authors chose a cutoff value $\geq 0.5$ for their index. Although the sensitivity of the proposed index was high (100\%), its positive predictive value was poor $(66 \%)$. Patients enrolled in the study by Pittet et al. were all from surgical units. It is possible that this colonization index is more useful in a unit with a known high incidence of candidemia. In units with a low incidence rate (medical ICU for example), associating clinical or/and biological signs with this index could enhance its accuracy. It would be legitimate to take a similar approach in children to offer more reliable, early preemptive or probabilistic treatments. Such studies in children are not currently available and should be done. Lortholary et al. reported a risk of being infected with a strain presenting reduced susceptibility to an antifungal therapy (Caspofungin or Fluconazole), in cases of recent exposure to one of these two drugs [24].

\section{Mortality}

In children, candidemia was associated with a $10 \%$ increase in mortality (95\% CI, 6.2-13.8\%), a 21.1-day increase in the average length of stay (95\% CI, 14.4-27.8 days), and an average increase in total hospital costs of $\$ 92,266$ per patient $(95 \% \mathrm{CI}, \$ 65,058-119,474)$ [7]. The mortality rate for candidemia was $30 \%$ for children and reached 43-54\% in infants [7]. As shown in Figure 1, the mortality rate due to Candida infection is highly correlated to the species of Candida and the child's age [6]. Overall, it should be noted that mortality rates appear higher in older patients regardless of the strain involved. Some authors reported that ICI linked to C. parapsilosis appeared to be less aggressive than cases linked to $C$. albicans $(27 \%$ vs. $47 \%$ mortality rate in children younger than 13 years; $\mathrm{n}=144$ ) [6]. However, Dutta et al. [15] showed, in a series of 108 children, no difference in terms of 30-day mortality between strains of Candida. Hospitalization in the PICU at the time of diagnosis of invasive candidiasis and the presence of an arterial catheter were independent risk factors for increased mortality [25]. High mortality rates have been observed in specific populations, and some authors have identified ethnic origin as a possible risk factor for developing ICI, especially in Filipino patients [26]. No other studies have confirmed these data.

\section{Candidiasis and children in pediatric oncology}

In pediatric oncology units, there often are more yeast infections than mold infections. In the study by Mor et al. [10], concerning 75 children with IFI and malignancy pathologies, positive blood cultures for yeast were obtained in $100 \%$ of infected cases. The main underlying diagnoses associated with yeast infections were acute myeloid leukemia (AML) and neuroblastoma (26.7\% each); five patients (older than aged 15 years, with invasive yeast infections) underwent hematologic stem cell transplantation (HSCT). Sung et al. [27] performed a survey of the available data from the pediatric cancer population (more specifically patients with AML) and IFI. They reported that during the induction and consolidation phases of treatment, respectively, $10 \%$ and $6 \%$ of children developed Candida infection. In this study, Candida spp. represented $25.9 \%$ of infection-related mortality (overall 11\% $\pm-2 \%$ ). The authors observed that in the case of intensive timing induction phase, compared with standard timing induction, the rate of yeast infections can increase 2.5 -fold $(8.4 \%$ vs. $19 \% ; p<0.01)$. So, the timing of the chemotherapy, regardless of dose, has an impact on the patient's risk for developing IFI. In children hospitalized in the PICU, the existence of an underlying malignancy is very important and increases from $17.5 \%$ to $46 \%$ the predicted probability of ICI [3].

\section{Invasive Aspergillosis infections in PICU}

There is little specific data available in the literature regarding children with IAI [5]. Furthermore, the available data are not homogeneous (definition, incidence, concerned population) making analysis difficult. Clear incidence of IAI in children with or without a hematologic underlying disease, or in the PICU, is not easy to 


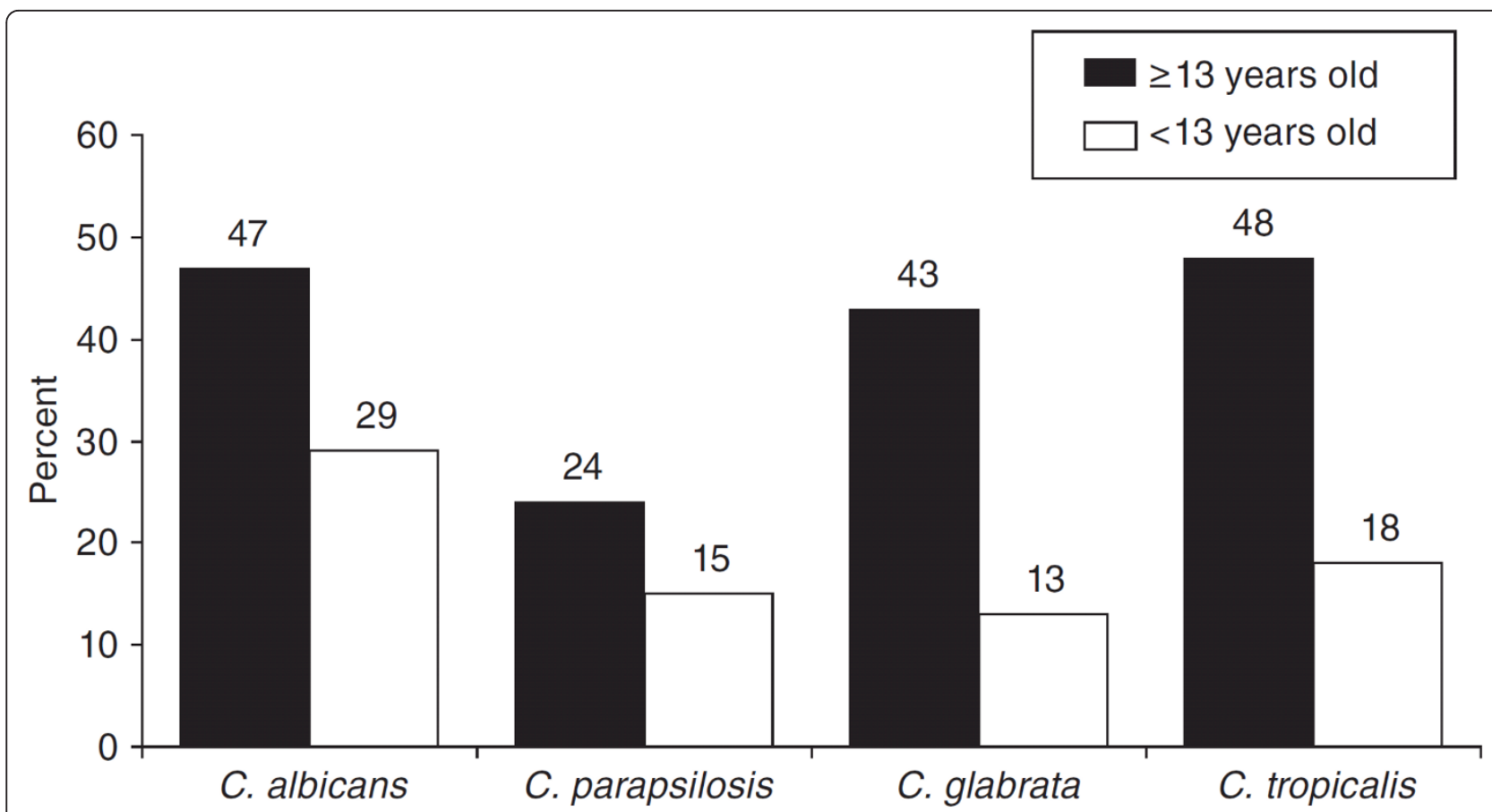

Figure 1 Mortality associated with type of Candida spp. among patients with candidemia younger $(n=144)$ and older $(n=1,447)$ than 13 years [6].

find. Some authors report the overall incidence, others the incidence in a specific subpopulation, whereas other papers give the proportion of children with IAI in specific conditions, i.e., presence of an underlying disease (such as AML or acute lymphoid lymphoblastic, for example). Another limitation is that definitions and care have changed over the decades. The largest study concerns 139 cases of IAI in children and only reports data until July 1, 2005 [1].

\section{Epidemiology}

Studies report a three- to fourfold increase in the incidence of IAI during the past decade [5,28], mainly attributable to the improvement of the quality of treatment and the survival rate of immunocompromised patients. In 2006, the annual incidence of IAI in children was $0.4 \%$ in the United States. Three quarters of these patients were immunosuppressed or suffered from oncological diseases [5]. In 2008, Crassard et al. [29] published a series of 24 cases of proven or probable IAI in children hospitalized in a pediatric hematologic department during a period of 15 years (1986-2000). Interestingly, the median interval between the onset of the malignancy and the diagnosis of IAI was 8.5 months. Fifty percent of infected patients had ALL or AML. Ten children underwent HSCT before the occurrence of IAI. Overall, 15 children (62.5\%) died. The mortality attributable to IAI was estimated to be $37.5 \%$ (9 children), $60 \%$ of overall deaths. The incidence of IA varied according to the underlying disease: $5.35 \%$ in AML, $1.5 \%$ in ALL. Other studies reported the same variation in incidence of IAI according to the underlying disease: $4 \%$ in AML and 1\% in ALL for Abbasi et al. [30], and 3.7\% in AML and $0.6 \%$ in ALL for Zaoutis et al. [31].

There are conflicting results in the literature regarding the most commonly identified species of Aspergillus in pediatric IAI. The most common strains observed in the pediatric population are A. fumigatus, A. nidulans, $A$. flavus, $A$. terreus, and $A$. niger. The largest contemporary study reporting IAI in children showed, as reported in adults series, A. fumigatus as the first causative agent in this disease (Figure 2) [1]. A. flavus was considered as the first causative organism in two previous studies $[32,33]$. In children, $A$. fumigatus seems to be the most common species encountered in the pulmonary form of the disease. A. flavus is predominantly found in skin infections [1]. Specific consideration must be given to $A$. niger whose incidence can reach $6.5 \%$ in septic granulomatous disease [31].

The most frequent localization was the lung, ranging from $59 \%$ to $91.6 \%$ of infections $[1,30,33,34]$. Walmsey reported predominance of up to $41 \%$ for IAI in skin lesions [33]. However, this was not confirmed by others publications, which found respectively $10 \%$ [1] and $20 \%$ [30] of cutaneous aspergillosis.

More anecdotic localizations (but not necessarily less dangerous or difficult to treat) have been described: 


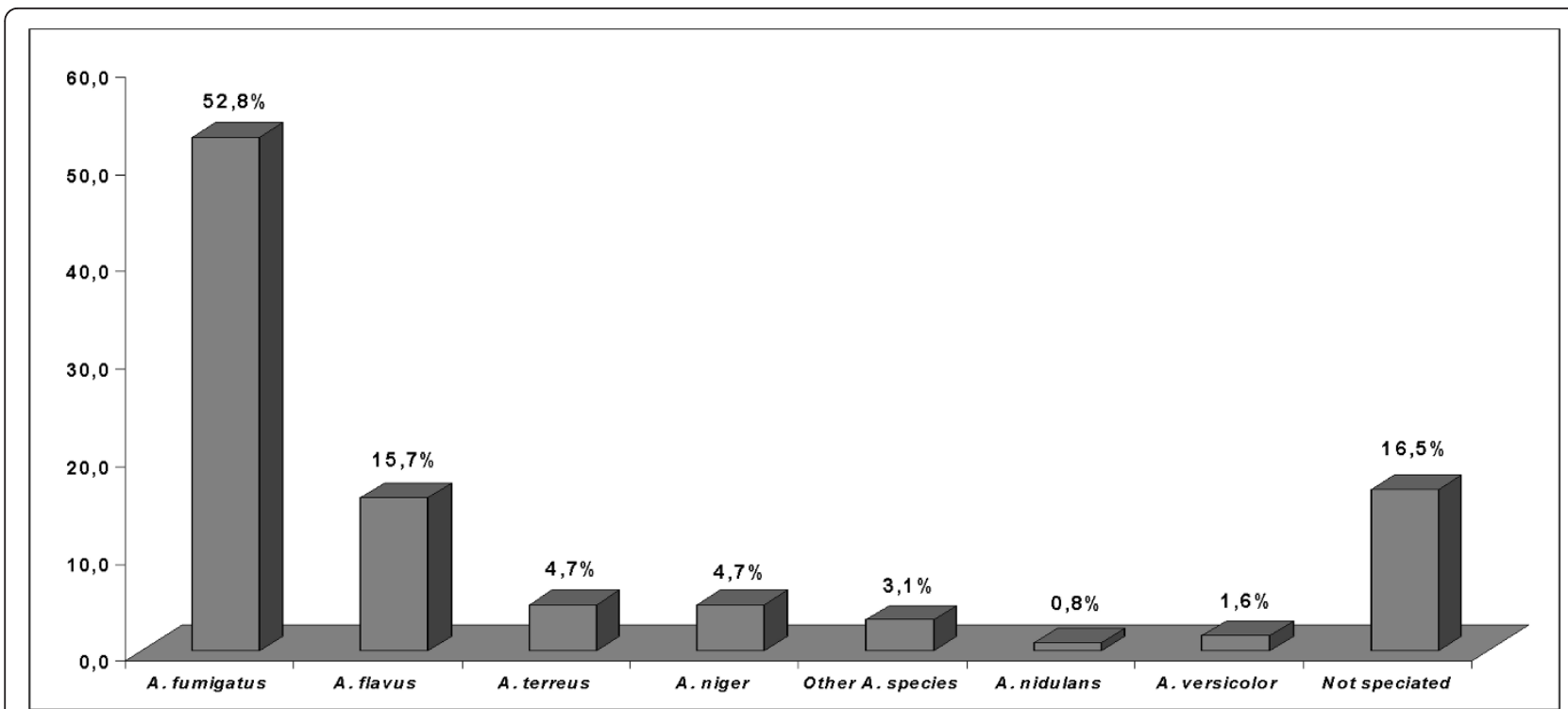

Figure 2 Aspergillus species encountered in invasive aspergillosis in 139 children [1].

cerebral, tracheobroncheal, renal, bone, endocardial, blood, and eye. Dotis et al. performed a systematic review of the literature for children with central nervous system Aspergillosis [35], identifying 90 cases since 1950. When considering children of 1 year or more, leukaemia (ALL statistically more frequently than AML) was the predominant underlying condition, followed by solid tumors, liver transplantation, chronic granulomatous disease, other hematological disorders, and various other conditions. Figures 3 and 4 summarize the underlying conditions encountered in the 139 cases of IAI reported by Burgos et al. [1]

\section{Risk factors for IA}

Risk factors for IAI are well known in both the adult and pediatric population. It is fundamental to understand that immunocompromised children can contract community- or hospital-acquired infections (source: construction work, renovation, air conditioning system contaminated). Risks factor include presence of several underlying diseases and their treatments,: hematologic malignancies, either primary or relapse, allogeneic bone marrow transplantation [34]; granulocytopenia, corticosteroids for malignancy but also autoimmune disease, immunosuppressive therapies, immunodeficiencies, such as chronic granulomatous disease, severe combined immunodeficiency, and organ transplantation, such as heart-lung transplantation [36]. There is evidence in the literature that the risk of IAI increases with higher doses of steroids (most often used in bone marrow transplantation) notably beyond a dose of prednisone $>2 \mathrm{mg} / \mathrm{kg} / \mathrm{j}$ [34]. Cushing syndrome because of its endogenous high secretion of cortisol can favor development of IA [36].
Some risk factors, such as persistent neutropenia, CMV infection, prolonged antibiotic administration, viral respiratory infection, HIV infection, and prior colonization with Aspergillus, are confounding factors with hospitalization in PICU or with the underlying malignancy itself [28]. Patients with AML and relapsed ALL are particularly at risk for IAI [31].

\section{Mortality}

Within the past decade in the United States, there has been a $357 \%$ increase in deaths related to IAI, regardless of the patient's age [34]. Risk factors for overall mortality in pediatric patients with IAI are summarized in Table 2. Patients with IAI have a $20 \%$ increase in mortality rate, a 13.5-fold increase in relative risk for death. Paediatric patients with IAI had a longer median length of hospital stay than immunocompromised children without IA (respectively 16 days and 3 days) [31]. Even with appropriate treatment, therapeutic response to IAI rarely exceeds $50 \%$. In the study by Burgos, the mortality rate for treated patients reached $52.5 \%$ [1]. Lin et al. [37] reported an overall IAI mortality rate of $58 \%$ when including patients of all ages and $68 \%$ in patients younger than aged 20 years. The mortality rate varied according to the underlying disease: $88.1 \%$ in cases of disseminated aspergillosis or CNS involvement, $86.7 \%$ in cases of bone marrow transplantation, $85.7 \%$ in HIV infection or AIDS. Highly active antiretroviral therapy (HAART) has profoundly transformed the incidence and prognosis of IAI in patients with HIV and AIDS.

The overall mortality rate for children with AML and ALL is quite low (respectively $3 \%$ and $1 \%$ ). However, if children with AML or ALL develop IAI, the mortality 


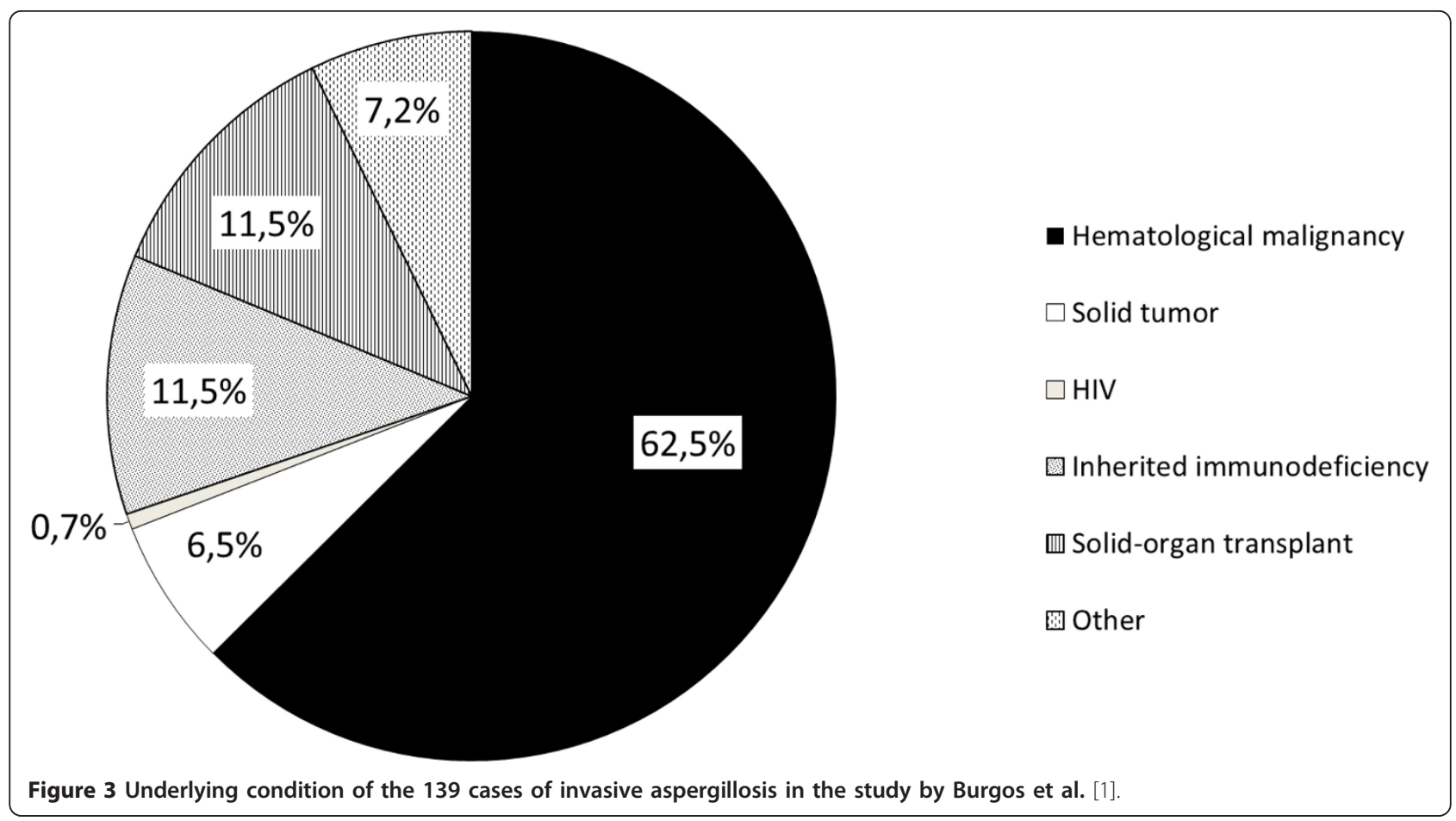

rate increases 5-fold for AML and 14-fold for ALL (respectively to $20 \%$ and $21 \%$ ) [5,31].

CNS aspergillosis-related mortality is usually reported as exceeding $80 \%$ [37]. However, in the study by Dotis et al. [35], the overall mortality of cases published in the literature since the 1950 s was $65.4 \%$ with a strong difference between the periods before and after 1990 (respectively $82.8 \%$ vs. $39.5 \%$ ). This may be due to improved patient care. Table 2 summarizes the risk factors for mortality in IAI identified by Burgos et al. [1].

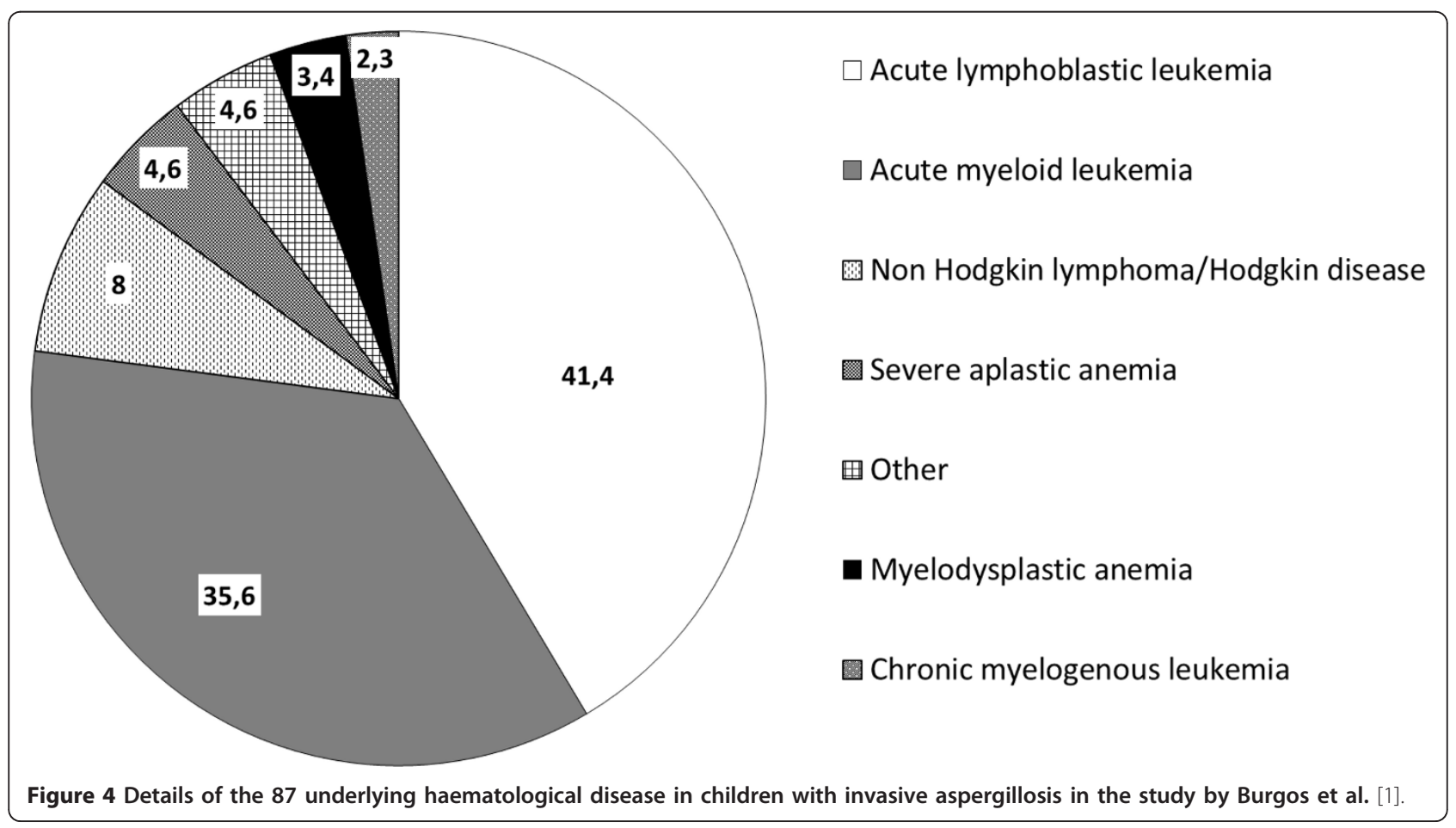


Table 2 Mortality risk factors in invasive aspergillosis (from [1])

\begin{tabular}{llll}
\hline Conditions & Alive $(\mathbf{n}=\mathbf{6 6})$ & Dead $(\mathbf{n}=\mathbf{7 3})$ & $\boldsymbol{p}$ \\
\hline Bone marrow transplantation & & & 0.001 \\
Autologous & $1(2)$ & $1(1)$ & \\
Allogeneic & $11(17)$ & $40(55)$ & \\
Graft-versus-host disease & $3(5)$ & $20(27)$ & 0.01 \\
Corticosteroid treatment & $42(64)$ & $62(85)$ & 0.033 \\
Immunodeficiency & $22(33)$ & $47(64)$ & 0.001 \\
Surgery after diagnosis & $38(58)$ & $23(32)$ & 0.045 \\
\hline
\end{tabular}

Data are numbers with percentages in parentheses unless otherwise indicated

\section{Conclusions}

The frequency and severity of IFI in children has increased steadily during the past 20 years. This is due to the higher prevalence of susceptible hosts who are kept alive with more aggressive therapy (cytotoxic, immunosuppressive), the specific treatment of hematopoietic stem cell transplantation, and the use of broad-spectrum antibiotics. Candida spp. and Aspergillus spp. are the most frequently identified fungi in children. The attributable mortality of each of these two invasive infections remains different mainly because the affected patients are different (more hematologic malignancies in patients with Aspergillus infection). Preemptive therapy has been well defined in cases of IAI, and recommendations have been provided by the IDSA [9]. The real challenge remains to identify patients with a high risk of invasive candidiasis in the PICU to propose targeted prophylaxis.

\section{Author details}

'Pediatric and Neonatal Intensive Care Unit, The Children's' Hospital of Bordeaux, Place Amélie Raba Léon, 33076 Bordeaux Cedex, France ${ }^{2}$ Division of Infectious Diseases, The Children's Hospital of Philadelphia, CHOP North Room 1527, Philadelphia, PA 19104, USA

\section{Authors' contributions}

TEZ has participated in the design, the editing, the drafting of the manuscript and language corrections; JG participated in the drafting, the proofreading and corrections of the manuscript, $\mathrm{JH}$ participated in the drafting, the proofreading and corrections of the manuscript, OT participated in the drafting, proofreading and corrections of the manuscript, $\mathrm{OB}$ participated in the design, the editing, the drafting, proofreading and corrections of the manuscript. All authors participated for the literature review, read and approved the final manuscript.

\section{Competing interests}

The authors declare that they have no competing interests.

Received: 10 October 2011 Accepted: 22 February 2012 Published: 22 February 2012

\section{References}

1. Burgos A, Zaoutis TE, Dvorak CC, Hoffman JA, Knapp KM, Nania JJ, et al: Pediatric invasive aspergillosis: a multicenter retrospective analysis of 139 contemporary cases. Pediatrics 2008, 121:e1286-e1294.

2. Neu N, Malik M, Lunding A, Whittier S, Alba L, Kubin C, et al: Epidemiology of candidemia at a children's hospital, 2002 to 2006. Pediatr Infect Dis J 2009, 28:806-809.
3. Zaoutis TE, Prasad PA, Localio AR, Coffin SE, Bell LM, Walsh TJ, et al: Risk factors and predictors for candidemia in pediatric intensive care unit patients: implications for prevention. Clin Infect Dis 2010, 51:e38-e45.

4. Filioti J, Spiroglou K, Panteliadis CP, Roilides E: Invasive candidiasis in pediatric intensive care patients: epidemiology, risk factors, management, and outcome. Intensive Care Med 2007, 33:1272-1283.

5. Steinbach WJ: Epidemiology of Invasive Fungal Infections in Neonates and Children. Clin Microbiol Infect 2010.

6. Zaoutis T: Candidemia in children. Curr Med Res Opin 2010, 26:1761-1768

7. Zaoutis TE, Argon J, Chu J, Berlin JA, Walsh TJ, Feudtner C: The epidemiology and attributable outcomes of candidemia in adults and children hospitalized in the United States: a propensity analysis. Clin Infect Dis 2005, 41:1232-1239.

8. Richards MJ, Edwards JR, Culver DH, Gaynes RP: Nosocomial infections in pediatric intensive care units in the United States. National Nosocomial Infections Surveillance System. Pediatrics 1999, 103:e39.

9. Pappas PG, Kauffman CA, Andes D, Benjamin DK Jr, Calandra TF, Edwards JE $\mathrm{Jr}$, et al: Clinical practice guidelines for the management of candidiasis: 2009 update by the Infectious Diseases Society of America. Clin Infect Dis 2009, 48:503-535.

10. Mor M, Gilad G, Kornreich L, Fisher S, Yaniv I, Levy I: Invasive fungal infections in pediatric oncology. Pediatr Blood Cancer 2011, 56:1092-1097.

11. Posfay-Barbe KM, Zerr DM, Pittet D: Infection control in paediatrics. Lancet Infect Dis 2008, 8:19-31.

12. Blyth CC, Palasanthiran $P, O^{\prime}$ Brien TA: Antifungal therapy in children with invasive fungal infections: a systematic review. Pediatrics 2007, 119:772-784.

13. Branger B: Enquête de prévalence nationale 2001 des infections nosocomiales chez les nouveau-nés et des enfants et adolescents de moins de 18 ans. Arch Pediatr 2005, 12:1085-1093.

14. Grisaru-Soen G, Sweed Y, Lerner-Geva L, Hirsh-Yechezkel G, Boyko V, Vardi A, et al: Nosocomial bloodstream infections in a pediatric intensive care unit: 3-year survey. Med Sci Monit 2007, 13:CR251-CR257.

15. Dutta A, Palazzi DL: Candida non-albicans versus Candida Albicans Fungemia in the non-neonatal pediatric population. Pediatr Infect Dis J 2011.

16. Singhi S, Rao DS, Chakrabarti A: Candida colonization and candidemia in a pediatric intensive care unit. Pediatr Crit Care Med 2008, 9:91-95.

17. Mahieu LM, Van Gasse N, Wildemeersch D, Jansens H, leven M: Number of sites of perinatal Candida colonization and neutropenia are associated with nosocomial candidemia in the neonatal intensive care unit patient. Pediatr Crit Care Med 2010, 11:240-245.

18. Pfaller MA, Castanheira M, Messer SA, Moet GJ, Jones RN: Variation in Candida spp. distribution and antifungal resistance rates among bloodstream infection isolates by patient age: report from the SENTRY Antimicrobial Surveillance Program (2008-2009). Diagn Microbiol Infect Dis 2010, 68:278-283.

19. Zaoutis TE, Greves HM, Lautenbach E, Bilker WB, Coffin SE: Risk factors for disseminated candidiasis in children with candidemia. Pediatr Infect Dis J 2004, 23:635-641.

20. Rex JH, Sobel JD: Prophylactic antifungal therapy in the intensive care unit. Clin Infect Dis 2001, 32:1191-1200.

21. Eggimann P, Garbino J, Pittet D: Management of Candida species infections in critically ill patients. Lancet Infect Dis 2003, 3:772-785.

22. Leon C, Ruiz-Santana S, Saavedra P, Almirante B, Nolla-Salas J, AlvarezLerma F, et al: A bedside scoring system ("Candida score") for early antifungal treatment in nonneutropenic critically ill patients with Candida colonization. Crit Care Med 2006, 34:730-737.

23. Pittet D, Monod M, Suter PM, Frenk E, Auckenthaler R: Candida colonization and subsequent infections in critically ill surgical patients. Ann Surg 1994, 220:751-758.

24. Lortholary O, Desnos-Ollivier M, Sitbon K, Fontanet A, Bretagne S, Dromer F: Recent exposure to caspofungin or fluconazole influences the epidemiology of candidemia: a prospective multicenter study involving 2,441 patients. Antimicrob Agents Chemother 2011, 55:532-538.

25. Zaoutis TE, Coffin SE, Chu JH, Heydon K, Zhao H, Greves HM, et al: Risk factors for mortality in children with candidemia. Pediatr Infect Dis J 2005, 24:736-739.

26. Fujitani S, Ricardo-Dukelow M, Kamiya T, Sullivan L, Low L: Ethnicity and other possible risk factors for candidemia at 3 tertiary care university hospitals in Hawaii. Infect Control Hosp Epidemiol 2006, 27:1261-1263. 
27. Sung L: Invasive fungal infections in children with cancer. J Pediatr 2010, 156:S68-S73.

28. Segal BH: Aspergillosis. N Engl J Med 2009, 360:1870-1884.

29. Crassard N, Hadden H, Piens MA, Pondarre C, Hadden R, Galambrun C, et al: Invasive aspergillosis in a paediatric haematology department: a 15-year review. Mycoses 2008, 51:109-116.

30. Abbasi S, Shenep JL, Hughes WT, Flynn PM: Aspergillosis in children with cancer: A 34-year experience. Clin Infect Dis 1999, 29:1210-1219.

31. Zaoutis TE, Heydon K, Chu JH, Walsh TJ, Steinbach WJ: Epidemiology, outcomes, and costs of invasive aspergillosis in immunocompromised children in the United States, 2000. Pediatrics 2006, 117:e711-e716.

32. Groll AH, Kurz M, Schneider W, Witt V, Schmidt H, Schneider M, et al: Fiveyear-survey of invasive aspergillosis in a paediatric cancer centre. Epidemiology, management and long-term survival. Mycoses 1999, 42:431-442.

33. Walmsley S, Devi S, King S, Schneider R, Richardson S, Ford-Jones L: Invasive Aspergillus infections in a pediatric hospital: a ten-year review. Pediatr Infect Dis J 1993, 12:673-682.

34. Steinbach WJ: Invasive aspergillosis in pediatric patients. Curr Med Res Opin 2010, 26:1779-1787.

35. Dotis J, losifidis E, Roilides E: Central nervous system aspergillosis in children: a systematic review of reported cases. Int J Infect Dis 2007, 11:381-393.

36. Muller FM, Trusen A, Weig M: Clinical manifestations and diagnosis of invasive aspergillosis in immunocompromised children. Eur J Pediatr 2002, 161:563-574.

37. Lin SJ, Schranz J, Teutsch SM: Aspergillosis case-fatality rate: systematic review of the literature. Clin Infect Dis 2001, 32:358-366.

doi:10.1186/2110-5820-2-6

Cite this article as: Brissaud et al:: Invasive fungal disease in PICU: epidemiology and risk factors. Annals of Intensive Care 2012 2:6.

\section{Submit your manuscript to a SpringerOpen ${ }^{\circ}$ journal and benefit from:}

- Convenient online submission

- Rigorous peer review

- Immediate publication on acceptance

- Open access: articles freely available online

- High visibility within the field

- Retaining the copyright to your article

Submit your next manuscript at $\gg$ springeropen.com 